\title{
Erratum
}

\section{Root-freezing damage in the containerized nursery: impact on plantation sites $-\mathrm{A}$ review}

\section{F.J. BIGRAS ${ }^{1, *}$ and D. DUMAIS ${ }^{2}$}

${ }^{1}$ Natural Resources Canada, Canadian Forest Service, 1055 du P. E. P. S., Sainte-Foy (QC), Canada GIV 4C7; ${ }^{2}$ Ministere des Resources naturelles, de la Faune et des Parcs, Direction de la recherche forestière, 2700 Einstein, Sainte-Foy (QC), Canada, GIP 3W8; *Author for correspondence: (e-mail: fbigras@nrcan.gc.ca; phone: 418-648-2528; fax: 418-648-5849)

Published in New Forests Volume 30, Nos. 2-3, pp. 167-184, 2005.

Due to an unfortunate turn of events figure 1 (page 170) and figure 2 (page 179) were exchanged and therefore displayed with the wrong figure legend. Below you are to find figures 1 and 2 with the correct figure legend that should be treated as definitive by the reader.

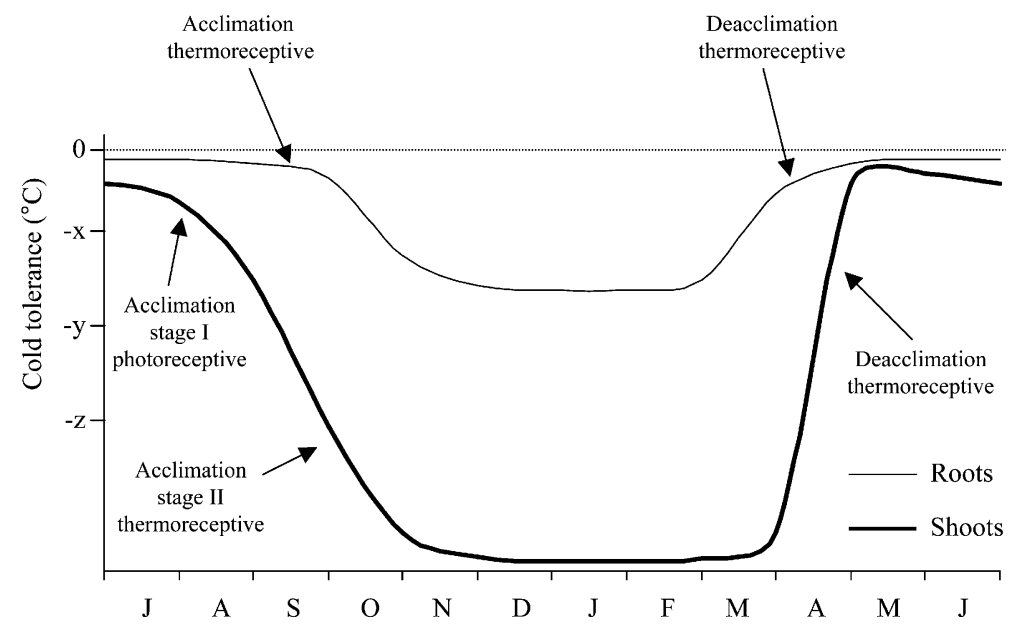

Figure 1. Theoretical hardening-dehardening curves for shoots (-) and roots (-) of conifer species growing in containers in northern countries. 


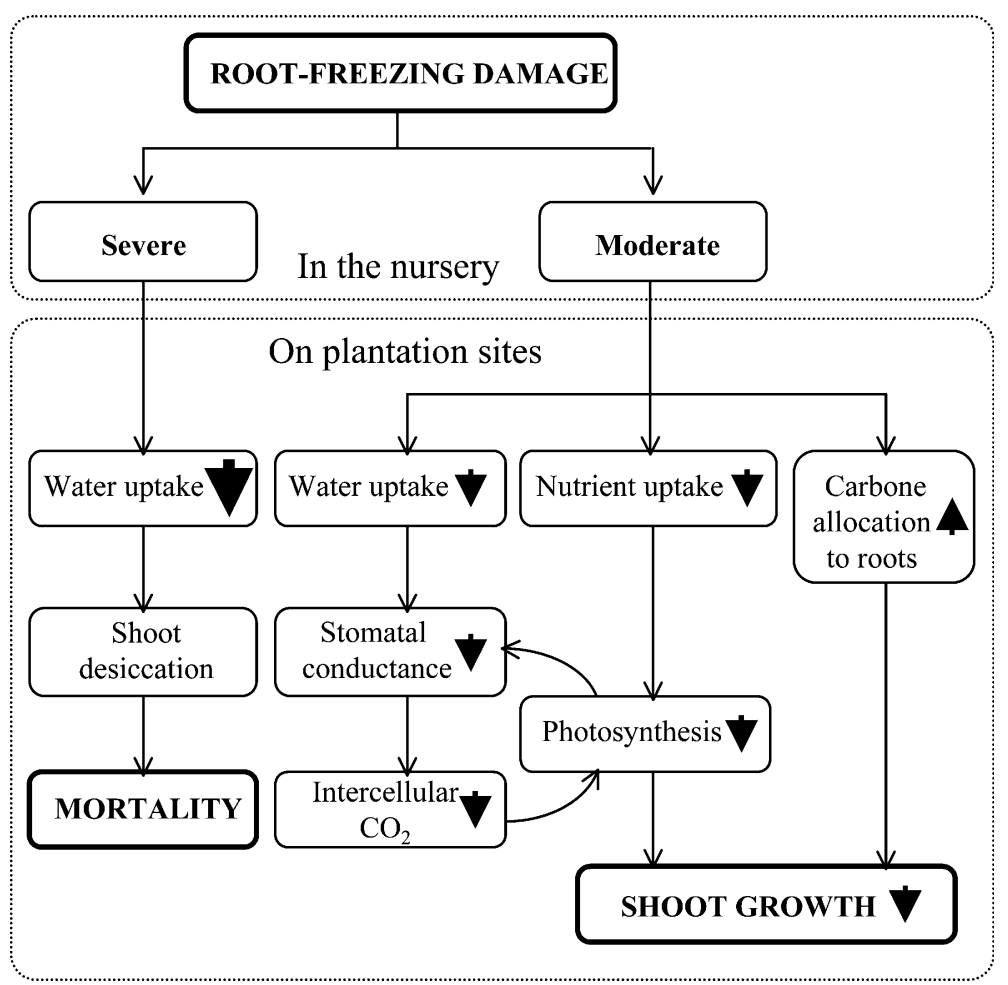

Figure 2. Impact of root-freezing damage occurring in the nursery on field performance of containerized confier seedlings. Fine arrows indicate the hypothetical sequence of morphological and physiological events after outplanting. Bold arrows show increase or decrease. 